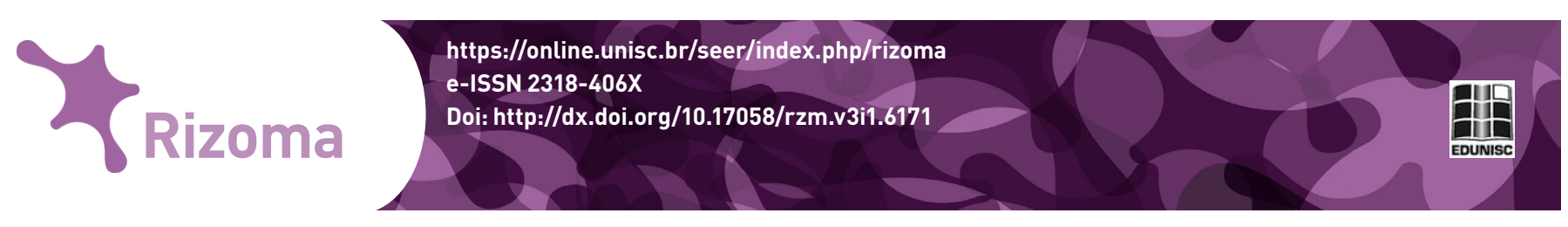

\title{
Entrevista
}

\section{Mario Carlón}

Doutor em Ciências Sociais pela Universidade de Buenos Aires, Mario Carlón é um pesquisador inquieto. Interessam-lhe, no âmbito da pesquisa, principalmente, as reconfigurações midiáticas e os novos lugares que se estabelecem nesta ambiência; o fim dos meios massivos e a emergências de novas formas de diálogo, caso das produções colaborativas, para ficarmos em um exemplo. Adjetivos como fértil e produtivo também se encaixam no perfil de Mario Carlón: em seu currículo, assina sozinho ou com parcerias, pelo menos oito livros, duas dezenas de capítulo e um número expressivo de artigos publicados em anais de congressos e revistas especializadas. Nesta entrevista à Rizoma, o pesquisador argentino discorre sobre conceitos como midiatização, narrativas transmidiáticas, crise na televisão e outros. As questões da entrevista foram redigidas em português e respondidas em espanhol. Na edição, optou-se por manter perguntas e respostas na língua original em que foram formuladas.

Você compartilha da perspectiva teórica da midiatização que explica os fenômenos comunicacionais levando em conta uma nova ambiência que gera novas práticas e novos comportamentos dos sujeitos que interagem com as mídias. Que tipos de marcas constitutivas são possíveis de observar na relação da sociedade com a mídia no contemporâneo?

Muchas, quizás la más importante es que la sociedad ya ha adoptado masivamente estos medios, en particular las redes sociales. No es algo que se pueda subestimar.

Neste contexto, emergem novas visadas, caso das narrativas transmidiáticas, na nomenclatura de Jenkys. Em sua perspectiva, tratam-se, as narrativas transmidiáticas, de uma característica desta nova ambiência, midiatizada, ou são, antes, uma face de uma processualidade mais ampla?

Creo que, en ciertos sentidos, lo que Jenkins define como narrativas transmediáticas es algo nuevo. Antes La industria producía transposiciones y adaptaciones, un discurso pasaba de un medio a otro con modificaciones, procedimiento que tiene antecedentes desde el origen del cine (por ejemplo, las transposiciones del Quijote). La proposición de Jenkis, en el contexto de la convergencia, es novedosa. Por un lado porque está la idea de que cada texto suma algo al todo (antes no era necesariamente así). Y por otro porque

Doutor em Ciências da Comunicação pela Unisinos. Diretor administrativo da SBPJor. Chefe do De-partamento de Comunicação Social e professor-pesquisador do Programa de Pós-graduação em Letras da Unisc.dsoster@uol.com.br

${ }^{2}$ Doutora em Comunicação pela PUC (RS). Professora e pesquisadora do Departamento de Comunicação Social e do Mestrado em Letras (UNISC). Atualmente é Coordenadora de Pós Graduação Stricto Sensu.fabi@unisc.br 


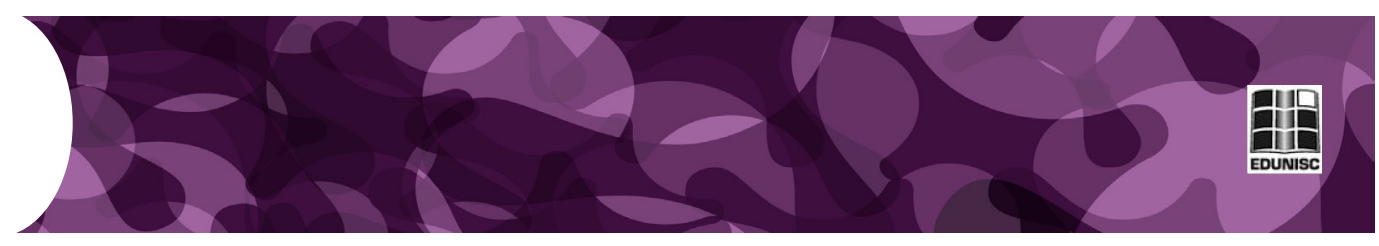

el análisis transmediático debe incluir también a las produccciones de los usuarios, que son impredecibles.

Usualmente, quando o assunto são narrativas transmidiáticas, a proximidade conceitual com os estudos fundadores (Todorov, Barthes etc.) fica no campo das nomenclaturas, provavelmente. Ou seja, pensamos em processualidades, ao invés de elementos estruturais, como, por exemplo, narradores. Em sua opinião, considerando o que foi posto, quem são, hoje, os narradores que até bem pouco tempo ocupavam as páginas, por exemplo, dos impressos?

La figura de narrador en sentido tradicional, al igual que la de autor, está en crisis. Por supuesto que permanentemente se realizan esfuerzos para reconstruirla. Pero eso no implica que los discursos que circulan actualmente, en las nuevas condiciones de circulación, no estén tensionando más a esas figuras productoras de discursividad.

Você diz que a TV não existe mais enquanto meio, como até então se conhecia, mas sim enquanto dispositivo. Que tipo de implicações isso causa? Como se pode compreender esta Tv que está surgindo?

La TV histórica en cuanto medio está en crisis, como sostuvo Verón. En ese sentido estamos en una etapa post-televisiva, en la que el poder ha pasado al espectador. Las nuevas instituciones que triunfan, como Netflix, han entendido esto: no pueden programar las prácticas del consumo (no pueden decidir en qué momento y bajo qué dispositivo se van a ver los discursos). Entonces lo que hacen es ofrecer esa posibilidad al espectador, para que sea él quien programa de acuerdo a sus tiempos y posibilidades. Es el triunfo del concepto on demand. Pero en cuanto a dispositivo y, lo que es más importante, en cuanto lenguaje, vivimos una época de plena vigencia del lenguaje cinematográfico. Todas las series que vemos, en una nueva narratividad seriada, se apoyan en el lenguaje cinematográfico en cuanto a conjunto de operaciones de montaje posibles.

Explique como a nova Tv, por demanda, estabelece relações distintas entre 0 ao vivo e o gravado. E como os gêneros dentro da grade televisiva podem ser (re)conhecidos dentro deste contexto, como por exemplo o telejornal que lida com o real?

El directo, que siempre fue el discurso menos atendido y estudiado, se ha adaptado muy bien a esta época. Fue mucho menos afectado por la crisis del medio televisión que el grabado, porque lo que es en directo tiene un sentido específico si se lo ve en directo. La televisión en directo tiene muchas más posibilidades de programar el consumo que el grabado, mientras que lo que transmita tenga interés. Yo creo que fue menospreciado y dejado de lado en la época anterior porque su discursividad desafía a las teorías discursivas antropocéntricas. El discurso del directo sólo puede ser conceptuado desde una teoría no antropocéntrica en mi opinión, y eso es lo que intenté hacer. El grabado sobrevive, pero es muy difícil desde el grabado programar el 
consumo. La nueva forma del grabado, que es el on demand, ha asumido que debía brindarle poder al espectador. Hay muchas cuestiones más en juego en este tema, como que vivimos en una época en la que el presente tiene un nuevo valor y por eso el directo se ha adoptado tan bien, pero es difícil tratarlas en estas breves respuestas.

Você fala sobre o fim dos meios massivos e sobre o surgimento destes como dispositivos no contexto contemporâneo. Neste sentido, o que se pode dizer das mídias em redes sociais que já nascem neste novo tempo e na nova lógica comunicacional?

Los llamados "nuevos medios" se han adaptado muy bien a su época porque son muy distintos de los medios masivos. Hay muchos motivos, pero brindo rápidamente dos explicaciones. La primera, es que antes que medios en sentido tradicional, que brindan contenidos, son plataformas para que los sujetos produzcan sus propios contenidos. Es decir que lo que las redes sociales hacen es poner a disposición de sujetos medios de comunicación para que ellos hagan lo que quieran con ellos. La segunda, es que permiten apropiarse muy fácilmente de los contenidos que circulan en la vida social. Yo creo que uno de los más importantes objetivos de la investigación hoy es interpretar los sentidos de las apropiaciones que realizan los sujetos (de prácticas como "compartir"), y que para hacerlo es necesario comprender que nuestra cultura actual, que más allá de la moderna y posmoderna es la contemporánea, está "formateada" por el arte contemporáneo (o, dicho en términos veronianos, que el arte contemporáneo es condición de producción de la cultura actual).

Muito recentemente, emergiu, em especial via redes sociais, uma discussão peculiar em torno da midiatização. Ou seja, a partir de Stig Hjarvard percebeu-se que, apesar de a midiatização, enquanto teoria, estar sendo discutida em outras partes do mundo, caso da Europa, os europeus desconhecem o trabalho que é feito pelos pesquisadores sulamericanos neste campo, apesar de sua perspectiva fundadora já a partir de Eliseo Verón e Antonio Fausto Neto. Você concorda com isso? Caso sim, a que se deve este isolamento cultural - deles e nosso?

Creo que es propio de la organización internacional del poder y del conocimiento. No me preocupa mucho esa situación de desinterés por lo que hacemos, que ya la hemos vivido en otros temas. Nuestra riqueza - pienso en términos borgeanos - reside en que leemos todo lo que cae en nuestras manos, europeo o americano del norte (cosa que ellos mismos hacen entre sí muy poco), y en que esa situación nos permite realizar otras comparaciones y análisis. La teoría de las mediatizaciones y comunicación en América Latina ha demostrado estar muy aggiornada e incluso ir a la vanguardia en más de una oportunidad. Desde que publicamos "El fin de los medios masivos" con Carlos A. Scolari, inspirado en gran parte sobre el diagnóstico de Elisevo Verón del "fin" de la televisión, nos hemos dado cuenta de que es un libro único a nivel internacional, que no hay otro dedicado íntegramente y en 

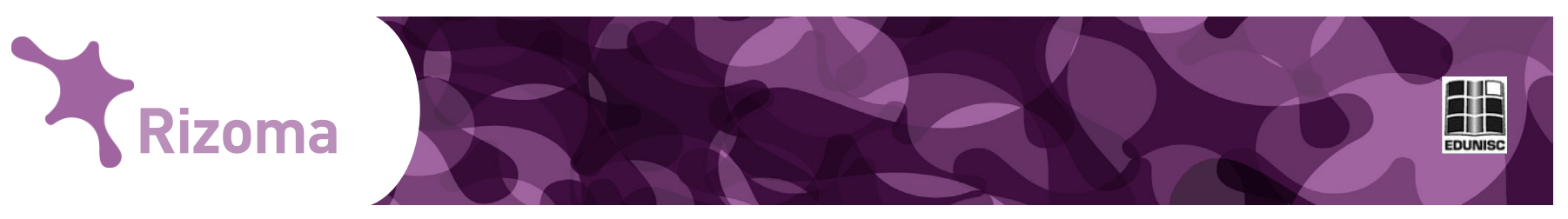

forma sistemática a pensar la crisis del conjunto de los medios (en el mismo año se publicó uno en el ámbito anglosajón dedicado al fin de la tv, pero no sobre el conjunto de los medios). Y el desarrollo mismo de la teoría de la mediatizaciones en América Latina, con Eliseo como fundador y teóricos como Fausto Neto y otros que hemos intentado seguir ese camino (también hay ahora nuevos autores, en Argentina y Brasil), no fue en absoluto un epifenómeno de los desarrollos europeos.

Ainda pensando em termos acadêmicos, e dialogando com a midiatização, você acredita que a produção acadêmica, dissertações e teses, principalmente, está dialogando a contento com as reconfigurações midiáticas em que estamos inseridos?

Creo que la teoría de las mediatizaciones se fundó en la era de los medios masivos y que fue extraordinaria para pensar ese período. Y que hay mucho para hacer en relación al nuevo ambiente mediático. Creo que estamos avanzando y vamos a seguir haciéndolo, pero también que hay que ser audaces y no subestimar el cambio que estamos viviendo. Eso no va a obligar a llevar adelante planteos nuevos. Ese es el desafío. 


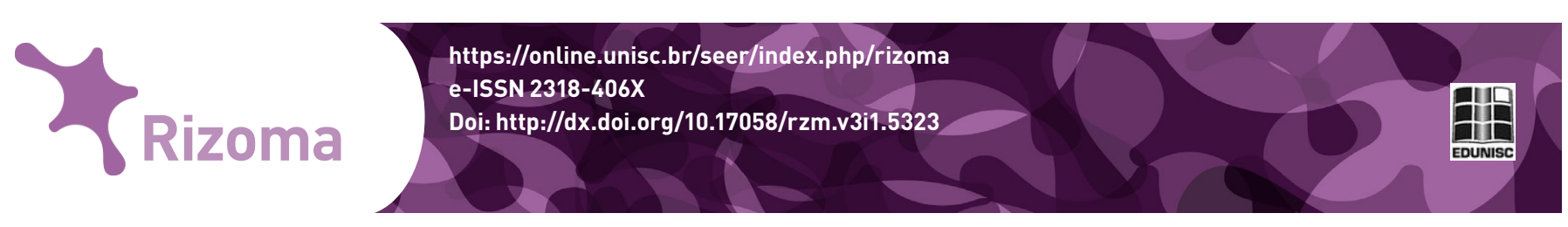

\section{Resenha}

\section{Crítica das Ligações na Era da Técnica, Ligações_Links_Liasions}

Resenha de Miranda, José de Bragança \& Cruz, Maria Teresa (org.) (2002) Crítica das Ligações na Era da Técnica, Ligações_Links_Liasions, Lisboa: Tropismos.

Um das maiores virtudes deste livro consiste, muito provavelmente, em convidar o(a) leitor(a) a refletir sobre um tema a partir de uma inscrição possível em duas áreas científicas importantes no âmbito genérico das Ciências da Comunicação, a sociologia da comunicação e a semiótica social. As duas quase que se abraçam ao mais fiel estilo de Vivien Leigh e Clark Gable no drama cinematográfico norte-americano de 1939, Gone with the wind. Se, à boa moda cinéfila, tivéssemos de escolher que disciplina mais se destaca, essa seria seguramente a semiótica social, pela insistência numa abordagem sensível à reprodução dos significados, neste caso da técnica na sociedade e na vida quotidiana. Naturalmente, este cruzamento temático não foi, de todo, deliberado. Em Crítica das Ligações na Era da Técnica, Ligações Links Liasions (Lisboa, Tropismos: 2001, ISBN: 972-95651-8-X, 336 pp. €19,50), José Bragança de Miranda e Maria Teresa Cruz colocam a questão das ligações no âmbito de uma sociedade marcada, como diz Paulo Cunha e Silva no prefácio, pelo novo «info-ser» (p.9), numa época em que «nunca tanto se falou de técnica» (p.11). Sendo o termo ligações um conceito tão vasto - e por que não ambíguo - de que forma é categorizada a ligação nesta contemporaneidade «profundamente marcada pelas tecnologias digitais»? (ibidem). O que talvez se torna importante constatar no final da leitura deste livro é o facto de muitas das questões colocadas permanecerem ainda sem resposta clara na atualidade.

Globamente, a obra estrutura-se em torno de cinco capítulos, onde vinte ensaístas refletem sobre diferentes tipos de ligação técnica: estranhas, livres, enredadas, perigosas e on-off. Na primeira, José Gil inscreve as relações que se pautam pela «loucura, crime e atracções estranhas (...) uma relação psicótica em que se investe imediatamente uma carga afetiva inconsciente à qual se responde de maneira semelhante» (pp.22-23). O tom de Gil recorda-nos algumas linhas de pensamento de diversos autores marcadamente ciber-pessimistas: «a cibercultura é uma nova cultura que convoca e ameaça absorver toda a experiência. Mais: ameaça reduzi-la e construir um outro mundo» (p.22). Considerações idênticas a autores como Blumer \& Coleman (cit. em Hibberd, 2003: 53), que defendem que a Internet não oferece o potencial revitalizador para a crise do modelo de comunicação política. Além de privilegiar o lado apolítico da técnica, José Gil parece não admitir que a sua utiliza-
Fábio Ribeiro'

' Completou o doutoramento europeu em 2013, na Universidade do Minho (UM), em Ciências da Comunicação, na área de especialização de Sociologia da Comunicação e Informação, depois de ter cumprido um período de atividades

de formação complementar no grupo de investigação PUBLIRADIO, da Universidade Autónoma de Barcelona. Coordena o Grupo de Trabalho dos Jovens Investigadores da SOPCOM, a Associação Portuguesa de Ciências da Comunicação e é investigador integrado do Centro de Estudos de Comunicação e Sociedade da UM. 